\title{
Vanadium Redox Flow Batteries with Different Electrodes and Membranes
}

\author{
A. Habekost ${ }^{*}$ \\ University of Education Ludwigsburg, Department of Chemistry, Reuteallee 46, D-71634 Ludwigsburg, Germany \\ *Corresponding author: A.Habekost@t-online.de
}

\begin{abstract}
There is strong interest in developing batteries to complement lithium ion and fuel cell batteries. Vanadium redox flow batteries (VRFBs) seem to be suitable as large-scale energy storage systems. In these systems, vanadium species act as both electrolyte and active material. Since 1980, the pioneer of VRFB, Maria SkyllosKazacos from the University of New South Wales in Australia, has published a vast number of papers about electrode materials, membranes and combinations of vanadium and other redox active species. In chemistry didactics, these investigations pose a significant challenge: it is hard to transform these innovative developments into sound and easy to create experiments. Three experiments are presented here to introduce students to the capabilities of VRFBs with different electrodes and membranes for battery development.
\end{abstract}

Keywords: Third-Year Undergraduate, Electrochemistry, Hands-on Learning/Manipulatives, Laboratory Instructions

Cite This Article: A. Habekost, "Vanadium Redox Flow Batteries with Different Electrodes and Membranes." World Journal of Chemical Education, vol. 6, no. 1 (2018): 8-13. doi: 10.12691/wjce-6-1-2.

\section{Introduction}

It is no secret that the need to change from coal technology to renewable power sources incorporated into our existing electricity grid poses a significant challenge to scientists, especially electrochemists and engineers.

Electrical power and energy storage systems, such as rechargeable lithium ion batteries, fuel cells and redox flow batteries (RFBs), complement renewable power sources such as solar photovoltaics and wind power generators. One of the pioneers of RFBs, Maria SkyllasKazacos from the University of New South Wales in Australia, concluded that "the main battery technologies that are attracting the most attention for medium- to large-scale-grid-connect energy storage applications are sodium-sulfur, lithium ion and vanadium redox flow batteries" [1]. With the rapid expansion of wind-generated power, e.g., offshore wind parks in the North Sea, utilities are looking for solutions that ensure the stability and reliability of the electrical grid.

The social need to push this "green growth" creates a corresponding challenge for chemistry didactics to introduce students into this technological evolution. In this text, we focus on RFBs, particularly on the most promising electrochemical system, vanadium RFBs (VRFBs).

In an RFB, the energy is stored in two solutions comprising two redox couples. Typically, RFBs consist of two reservoirs with the electroactive species circulating through the redox cell. A proton exchange membrane separates the anodic and cathodic compartment, preventing cross-mixing of the two electrolyte solutions. Figure 1 shows the schematic of an RFB.

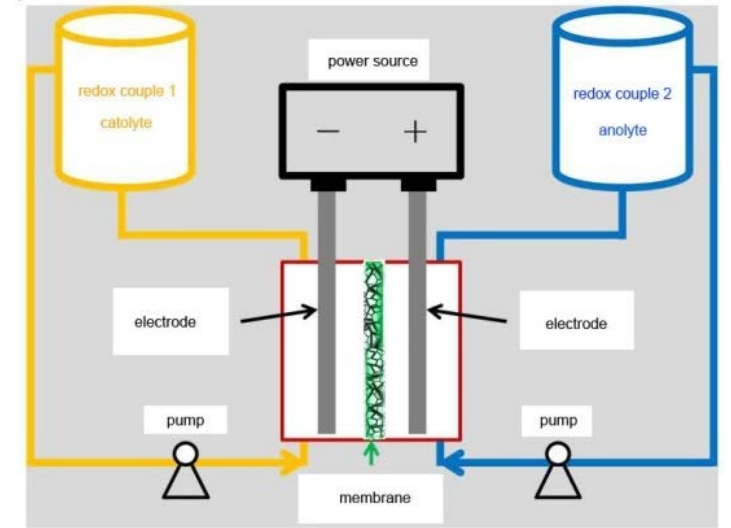

Figure 1. Schematic of a redox flow battery. The redox couple solutions are circulated through the redox cell containing the electrodes and the proton exchange membrane

RFBs belong to a species of rechargeable batteries that operate with redox couples as part of the electrolyte. In addition, hybrid RFBs contain a redox couple with one solid redox species.

Vanadium redox couples were first mentioned in 1884 by Charles Rennard [2]. In 1933, Pissoort patented a VRFB, and in 1954 a titanium chloride RFB was registered by Kangro [3]. Early systematic studies were conducted by Thaller from 1970 to 1984 as part of a NASA space program [4]. The first known successful demonstration of an RFB employing vanadium in both half cells was carried out at the University of New South Wales by Maria Skyllas-Kazacos.

In recent years, many combinations of RFBs have been proposed, including all-Cu [5,6,7], Zn/Ce [8,9,10], Fe/air [11], Zn/polyiodide [12], Fe/Br [13], Li/Br [14], Fe/V [15], 
metal-free organic-inorganic RFB [16], $\mathrm{H}_{2} / \mathrm{V}$ [17] and different organic redox couples such as polythiophene [18], quinone / hydroquinone [19,20].

Many redox systems have been investigated, but vanadium redox couples are the most attractive and commonly used. The electrochemical reactions at the positive and negative electrodes are given by eq. 1 and 2, respectively, while eq. 3 described the net reaction:

$$
\begin{gathered}
\text { Anode: } \mathrm{V}^{\mathrm{IV}} \mathrm{O}^{2+}+\mathrm{H}_{2} \mathrm{O} \square \mathrm{V}^{\mathrm{V}} \mathrm{O}_{2}{ }^{+}+2 \mathrm{H}^{+}+\mathrm{e}^{-}: \mathrm{E}_{0}=1 \mathrm{~V} \\
\text { Cathode: } \mathrm{V}^{3+}+\mathrm{e}^{-} \square \mathrm{V}^{2+}: \mathrm{E}_{0}=-0.25 \mathrm{~V}
\end{gathered}
$$

Net: $\mathrm{V}^{\mathrm{IV}} \mathrm{O}^{2+}+\mathrm{H}_{2} \mathrm{O}+\mathrm{V}^{3+} \leftrightarrow \mathrm{V}^{\mathrm{V}} \mathrm{O}_{2}^{+}+2 \mathrm{H}^{+}+\mathrm{V}^{2+}: \mathrm{E}_{0}=1.25 \mathrm{~V}(3)$

The bulk of investigation into VRFBs has been conducted at the University of New South Wales by Maria Skyllas-Kazacos and her coworkers over more than thirty years [21]. In their review article [22], Skyllas-Kazacos et al. summarized their main projects and results, e.g., about the kinetic and mechanistic of VRFB, about different electrodes and membranes, and about the technological implementations of VRFB.

Here we will only summarize some important: The electrochemical behavior of the V(III)/V(II) redox couple in $\mathrm{H}_{2} \mathrm{SO}_{4}$ strongly depends on the electrode used. On a glassy carbon electrode, the electron transfer rate constant $\mathrm{k}_{0}=7.5^{*} 10^{-4} \mathrm{~cm} / \mathrm{s}$, which means the electron transfer is irreversible. The electrolyte is critical with respect to the solubility of the vanadium salts. $\mathrm{H}_{2} \mathrm{SO}_{4}$ was found to be the best solvent for all vanadium species used in VRFBs. The concentration of the vanadium salts in $6 \mathrm{~mol} / \mathrm{L} \mathrm{H}_{2} \mathrm{SO}_{4}$ is between 2 and $4 \mathrm{~mol} / \mathrm{L}$.

There have been many investigations into the electrode materials. The compromise between economic and technical requirements favors graphite and carbon rods, graphite felts, carbon paper, carbon nanotubes, carbon nanofibers and graphene oxide [23]. These materials were found to function satisfactorily under both charge and discharge conditions in the acid electrolyte. However, a slow disintegration results during cell overcharging, causing the electrodes to deteriorate over months.

The main requirements of suitable electrode materials are stability in the acidic electrolyte, high oxygen and hydrogen overvoltage, and high electrical conductivity.

Various procedures were undertaken to enhance the chemical reactivity and wettability of the carbon electrodes: They were coated with different metals such as $\mathrm{Ir}^{3+}$ [24], $\mathrm{Pt}^{4+}, \mathrm{Pd}^{2+}, \mathrm{Au}^{4+}, \mathrm{Mn}^{2+}, \mathrm{Te}^{4+}$ and $\mathrm{In}^{3+}$ [25]. High hydrogen evolution rates were obtained on $\mathrm{Pt}, \mathrm{Pd}$, and $\mathrm{Au}$ modified electrodes, while the electrode modified by $\mathrm{Ir}^{3+}$ exhibited the best electrochemical behaviour for the various vanadium redox species.

In addition, carbon-based electrodes were heat treated with subsequent etching by $\mathrm{KOH}$ [26], or treated with hydrogen peroxide to form $\mathrm{C}-\mathrm{O}-$ and $\mathrm{C}=\mathrm{O}$-moieties [27].

The aim behind treating the carbon-based electrode is to enhance the wettability and electrochemical activity of low performance carbon and graphite electrodes. This was a significant milestone in achieving cost reduction for commercial applications of VRFBs.

Another way to improve the electrode material is to coat carbon with a conducting organic polymer as polyaniline [28].
The acidic electrolyte solution was also optimized by Skyllas-Kazacos [29]. The vanadium V(V) solution was optimized in terms of concentration, viscosity and temperature. It appears that 3.0-3.5 mol/L V(V) solutions in $6 \mathrm{M} \mathrm{H}_{2} \mathrm{SO}_{4}$ are sufficiently stable at temperatures up to $30{ }^{\circ} \mathrm{C}$. Higher vanadium concentrations need precipitation inhibitors such as sodium hexametaphosphate, $\mathrm{K}_{2} \mathrm{SO}_{4}$, $\mathrm{Li}_{2} \mathrm{SO}_{4}$ and urea [30].

The solvation structures of $\mathrm{V}^{2+}, \mathrm{V}^{3+}, \mathrm{VO}^{2+}$ and $\mathrm{VO}_{2}^{+}$ cations have been investigated by some researchers [31,32]. Both $\mathrm{V}^{2+}$ and $\mathrm{V}^{3+}$ are hydrated by six water molecules: $\left[\mathrm{V}\left(\mathrm{H}_{2} \mathrm{O}\right)_{6}\right]^{2+}$ and $\left[\mathrm{V}\left(\mathrm{H}_{2} \mathrm{O}\right)_{6}\right]^{3+}$. Because of the higher charge density, $\mathrm{V}^{3+}$ has shorter vanadium-ligand bond length (0.205 vs $0.215 \mathrm{~nm})$. The $\mathrm{VO}^{2+}$ cation has five water ligands in the first hydration shell, and an octahedral structure composed of five water ligands and one vanadyl oxygen atom. For the $\mathrm{VO}_{2}{ }^{+}$cation, two different structures are proposed: octahedral [ $\left[\mathrm{VO}_{2}\left(\mathrm{H}_{2} \mathrm{O}\right)_{6}\right]^{+}$ and bipyramidal $\left[\mathrm{VO}_{2}\left(\mathrm{H}_{2} \mathrm{O}\right)_{3}\right]^{+}$structures.

Despite these substantial advantages, VRFBs are unable to meet the requirements for use in vehicles. To enhance the energy density necessary for electrical vehicles, Skyllas-Kazacos developed another generation of RFBs, the vanadium bromide RFB with a mixture of $\mathrm{HCl}$ and $\mathrm{HBr}$ as electrolyte. The main advantage of this type of RFB is that it can employ an electrolyte concentration of over $4 \mathrm{~mol} / \mathrm{L}$ [33]. A polyhalide solution is used as the positive half-cell electrolyte, while a vanadium(II)/vanadium(III) chloride redox couple is used as the negative one. This doubles the energy density. To avoid forming bromine, a complexing agent is added to the electrolyte [34].

Great efforts were made to optimize the membrane: low cost and chemical stability were the main obstacles in commercializing the VRFB. Nafion membranes, known from fuel cells, have good chemical stability but are rather expensive. Although Nafion membranes are not permissive for vanadium ions, they well in contact with water. This leads to water diffusion through the membranes and may affect the electrical behavior of the VRFB. Skyllas-Kazacos measured the permeability of vanadium ions through different membranes [35]. The diffusion of vanadium ions through a membrane is an important parameter, because the permeability rate can drastically limit the cell efficiency. In addition, the authors found that the diffusion of $V(I V)$ and $V(V)$ species is higher than that of V(II) and V(III) species. This results in a transfer of the higher oxidized species after frequent charge and discharge cycles. In addition to Nafion membranes, many other materials were tested. An overview is given by Prifti et al. [36].

Finally, the stack design of RFBs is a further parameter in their commercialization: At the University of New South Wales, a $36 \mathrm{~V}$ and $5 \mathrm{~kW}$ VRFB was tested over 2.5 years in an electric golf cart. The stack design was as follows (Figure 2):

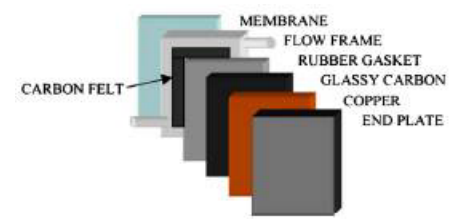

Figure 2. Components of a VRFB cell stack 


\section{Pedagogical Objectives}

In a didactical sense, batteries are very motivating for students. However, this topic requires as much knowledge about electrochemistry as about physics.

The aim of this article is to present versatile experimental setups to measure the redox processes at various electrodes, and the charge and discharge characteristics of the VRFB. We think that the pedagogical benefit of the described experimental procedures is a combination of the electrochemical and spectroscopic experiments - i.e., the use of cyclic voltammetry and the quenching of the electrogenerated chemiluminescence (ECL) of a ruthenium(II) complex as a function of the vanadium (IV) concentration. Therefore, students can estimate the sensitivities of this detection method. In addition, the combination of cyclic voltammetry and optical spectra may introduce students into the modern field of spectroelectrochemistry.

\section{Experiments}

Chemicals: Vandium(III)chloride (Sigma Aldrich 208272), Vanadium(IV)oxide sulfate hydrate (Sigma Aldrich 233706), Tris(2,2'-bipyridine)ruthenium(II)hexafluorophosphate (Sigma Aldrich 754730)

Carbon felt PGF 5x1.200mm (CGT carbon GmbH, Asbach, Germany)

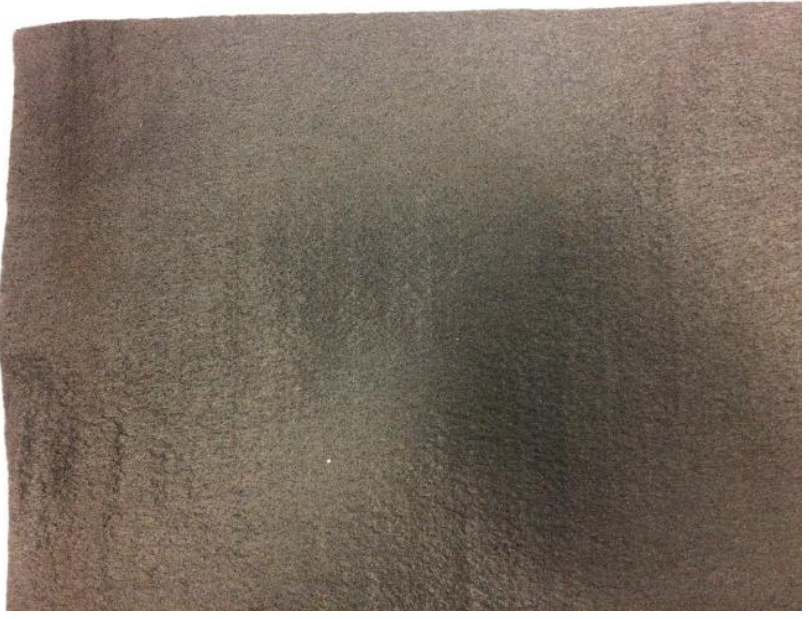

Figure 3. Carbon felt

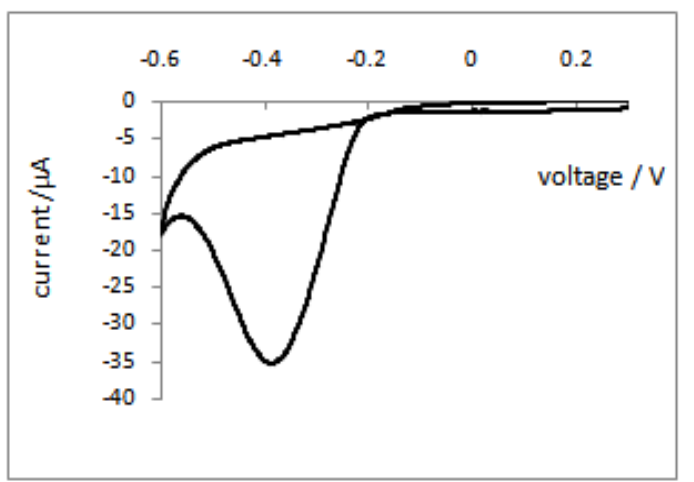

\section{Materials:}

Cyclic voltammetry: Potentiostat ( $\mu$-STAT 400, DropSens), screen-printed electrodes (SPE): DS 110 (graphite as working electrode WE), DS 110D (single walled carbon nanotubes SWCNT as WE), DS CNT-Au (nano gold on carbon nanotubes as WE), DS Au-Bt (low temperature gold as WE).

Electrogenerated chemiluminescence: ECL-potentiostat ( $\mu$-STAT ECL, DropSens)

Spectroelectrochemical setup: A fibre passed the light from the spectrometer (Kontron 432) through the transparent SPE (DRP AUTR 10, DropSens) fixed in the transmission cell with focusing lens and fibre optics (DRP-TRANSCELL, DRP-CLENS, DRP-TFIBER, DRPRPROBE, DropSens). A second fibre opposite guided the beam into a photomultiplier (Hamamatsu, R4220P with power supply: MH5781). The first fibre consisted of six single fibre bundles around a single reflection fibre to collect the reflected light beam to control the incident light intensity via another photomultiplier.

Data logging system (CASSY from Leybold didactic, Hürth, Germany)

\section{Didactic setup:}

U-tube with ceramic frit (homebuilt), platinum grid (Hedinger, Germany)

\section{Hazards}

Vanadium(III): Non-flammable

Vanadium(IV)oxide sulfate hydrate: carcinogenic and mutagenic

\subsection{Cyclic voltammetry (CV) and electrogenerated chemiluminescence (ECL)}

Figure 4 shows the cyclic voltammograms of vanadium(III) and vanadium (IV) with a graphite WE. It is obvious, that for V(III) and V(IV) the oxidation (anodic) and reduction (cathodic) peaks fail. This means that the reduction of $\mathrm{V}$ (III) to $\mathrm{V}$ (II) and the oxidation of $\mathrm{V}$ (IV) to $\mathrm{V}(\mathrm{V})$ are irreversible processes on graphite. In contrast, on gold (Au-Bt SPE) the reduction peak of V(V) to V(IV) appears (Figure 5), but the voltage difference between the anodic and cathodic peak is about $700 \mathrm{mV}$. Following the theory by Nicholson and Shain [37], this difference also indicates an irreversible electron transfer.

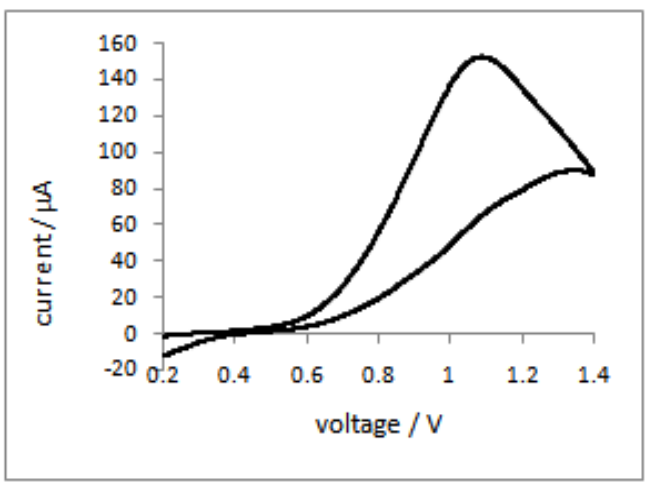

Figure 4. CV of vanadium (III) (left) and vanadium (IV) on graphite (right). The absence of the anodic (Figure 4, left) and cathodic current peak (Figure 4, right) indicates that the reduction $\mathrm{V}(\mathrm{III}) \rightarrow \mathrm{V}(\mathrm{II})$ and the oxidation $\mathrm{V}(\mathrm{IV}) \rightarrow \mathrm{V}(\mathrm{V})$ are irreversible on graphite. Scan rate $50 \mathrm{mV} / \mathrm{s}$ 


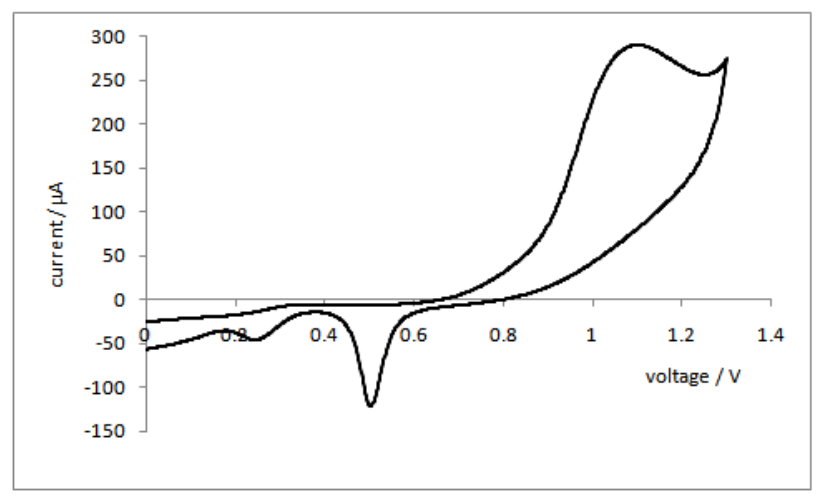

Figure 5. CV of vanadium (IV) on gold (Au-BT). The small cathodic current peak indicates that the oxidation $\mathrm{V}(\mathrm{IV}) \rightarrow \mathrm{V}(\mathrm{V})$ is irreversible. Note that the cathodic peak at $0.5 \mathrm{~V}$ results from the sulphuric acid

If the CNT-Au-SPE (Figure 6) is treated with 30\% $\mathrm{H}_{2} \mathrm{O}_{2}$ or with conc. $\mathrm{KOH}$, both the anodic and cathodic current peaks (at $0.9 \mathrm{~V}$ and-0.1 V) increase (Figure 7):

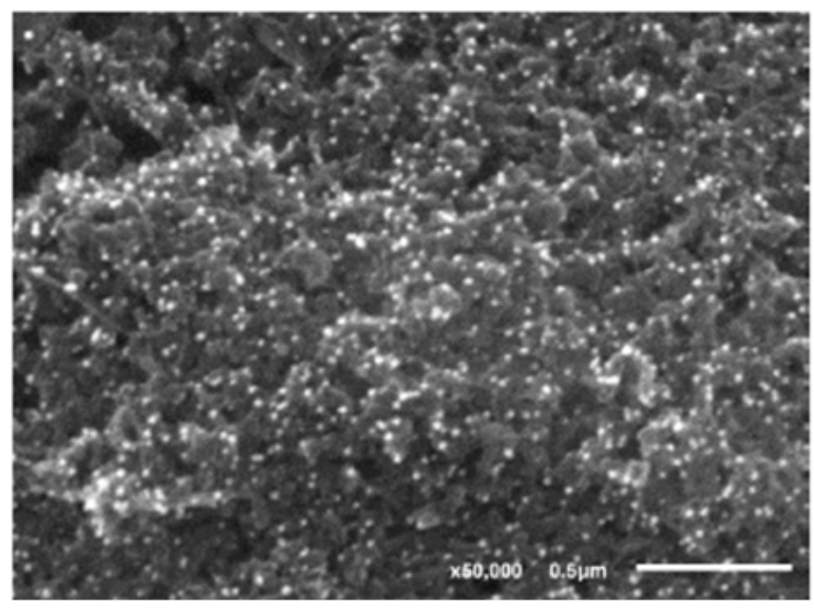

Figure 6. Carbon nanotubes, decorated with nano gold (SEM kindly from DropSens)

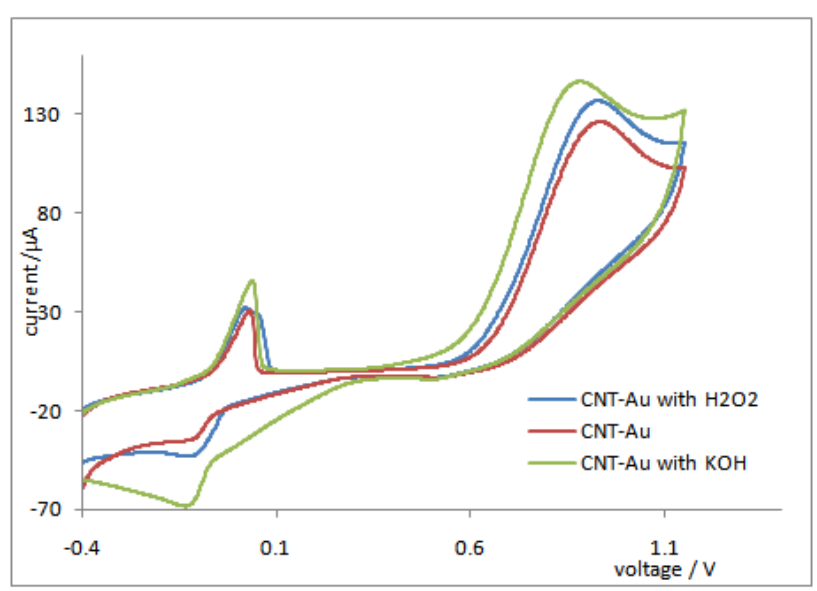

Figure 7. CV vanadium (IV) at different treated carbon nanotubes. The anodic peaks around $0 \mathrm{~V}$ result from $\mathrm{C}=\mathrm{O}$ and $\mathrm{C}-\mathrm{O}$ moieties on the CNTelectrode

A secondary aspect is the elegant detection of $\mathrm{V}(\mathrm{IV})$ with electrogenerated chemiluminescence (ECL): $60 \mu \mathrm{L}$ of a $100 \mu \mathrm{mol} / \mathrm{L}$ solution of Tris(2,2'-bipyridine)ruthenium(II) hexafluorophosphate in sulphuric acid shows a pronounced ECL beginning at about $0.75 \mathrm{~V}$ (Figure 8, solid line). By adding $5 \mu \mathrm{L}$ of a $100 \mu \mathrm{mol} / \mathrm{L} \mathrm{V(IV)} \mathrm{solution} \mathrm{in} \mathrm{sulphuric}$ acid, the ECL is quenched (dotted line): $\mathrm{Ru}(\mathrm{II})$ reacts with $\mathrm{V}(\mathrm{IV})$ to form Ru(III) and V(III).

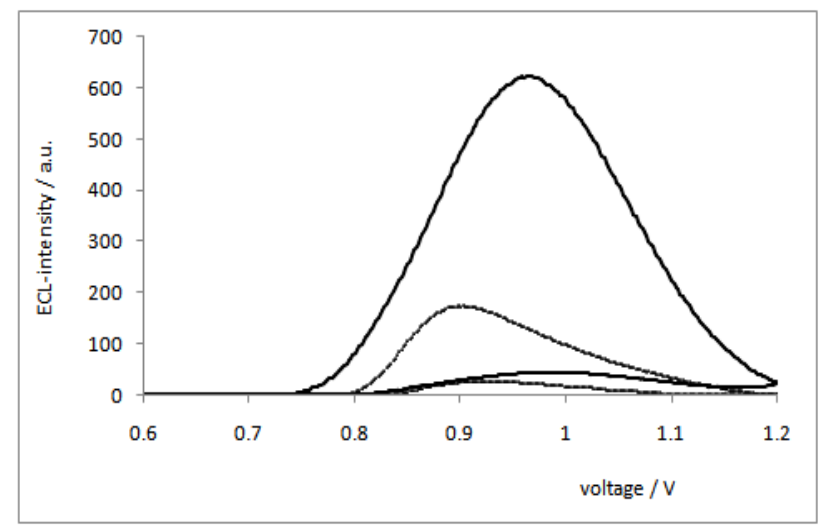

Figure 8. Solid line: ECL of $\left[\mathrm{Ru}(\mathrm{bpy})_{3}\right]^{2+}$ alone $(100 \mu \mathrm{mol} / \mathrm{L})$, dotted line $\left[\mathrm{Ru}(\mathrm{bpy})_{3}\right]^{2+}$ with $30 \mu \mathrm{mol} / \mathrm{L} \mathrm{V(IV)}$

\subsection{Spectroelectrochemistry}

The UV spectra of various vanadium species are published in [38]. Table 1 shows $\lambda_{\max }$ of $\mathrm{V}^{2+}, \mathrm{V}^{3+}, \mathrm{V}^{4+}$ and $\mathrm{V}^{5+}$.

Table 1. $\lambda_{\max }$ of various vanadium species.

\begin{tabular}{|c|c|}
\hline Compound & $\lambda_{\max } / \mathrm{nm}$ \\
\hline $\mathrm{V}^{2+}$ & 855 \\
\hline $\mathrm{V}^{3+}$ & 610 \\
\hline $\mathrm{V}^{4+}$ & 765 \\
\hline $\mathrm{V}^{5+}$ & 390 \\
\hline
\end{tabular}

In a spectroelectrochemical measurement, the electrochemical reaction $\mathrm{V}^{4+} \rightarrow \mathrm{V}^{5+}$ can be directly observed twice: As V(IV) is oxidized, both the current and the absorbance around $390 \mathrm{~nm}$ increase. This is reflected in Figure 9. In the back scan from $1.3 \mathrm{~V}$ to $0 \mathrm{~V}$, the absorbance remains almost constant, indicating that the reverse reaction does not occur. This corresponds to the $\mathrm{CV}$ in Figure 5.

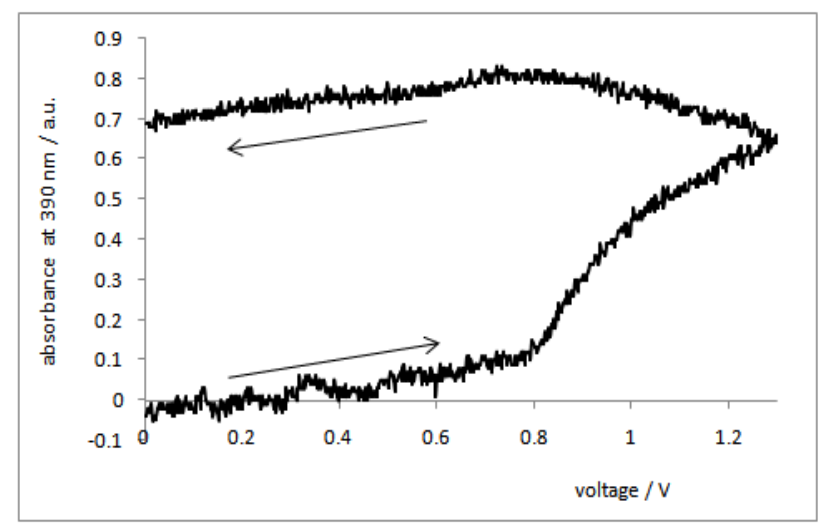

Figure 9. Absorbance at $390 \mathrm{~nm}$ as a function of the voltage (SPE: AuAt)

Figure 10 shows the absorbance at different wavelengths as a function of the applied voltage. This corresponds to the absorption spectra of $\mathrm{V}^{5+}$ (see insert of Figure 10). 


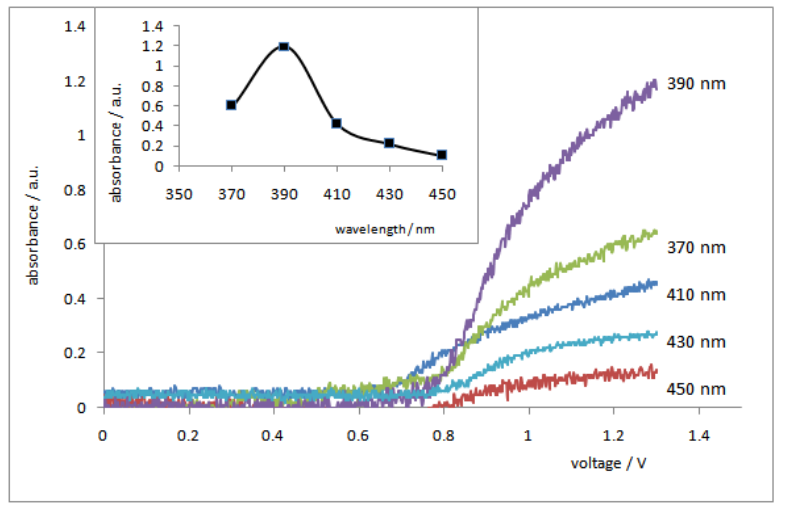

Figure 10. Absorbance of the oxidation product of $\mathrm{V}^{4+}$ at different wavelengths as a function of the applied voltage. Insert: Absorption spectra derived from the absorbance vs voltage curves

\subsection{Charging and Discharging of Vanadium Redox Flow Batteries}

Figure 11 shows the experimental setup of a "didactic" VRFB. The main components are a fuel cell, two pumps for circulating the vanadium solutions, two storage tanks with the acidic $\mathrm{V}^{3+}$ and $\mathrm{V}^{4+}$ solutions, a power supply for charging, a motor as a load and a data logging system. The electrodes of the cell are platinum grids or carbon felts that can be easily changed.

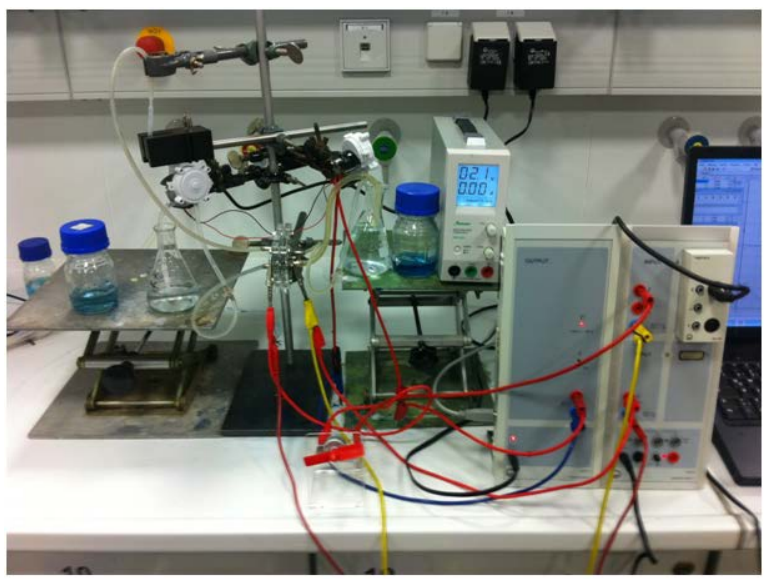

Figure 11. Experimental setup VRFB. From left to right: Pumps, reservoirs for the vanadium solutions, cell (between the pumps), power supply for charging, motor and data logging

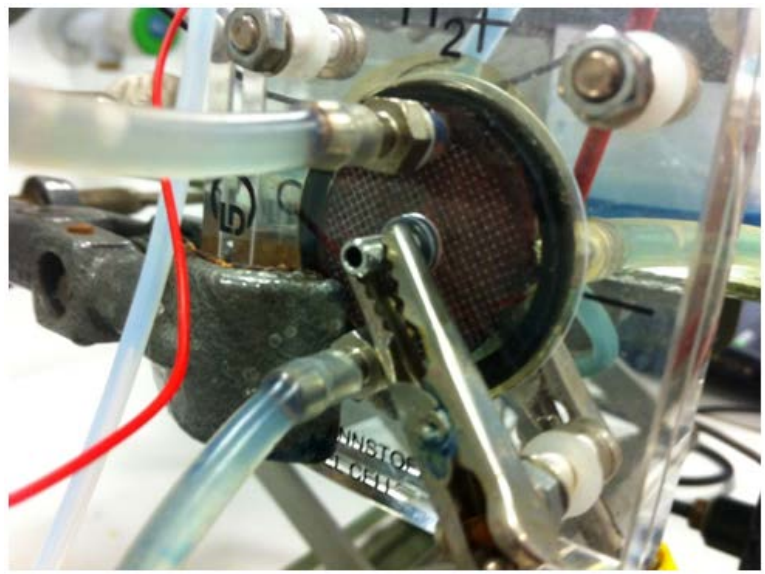

Figure 12. One part of the used cell with two hoses, the metal pick-up electrode and the carbon felt electrode. All compounds are mounted in a Plexiglas chamber. The alligator clip is connected with the data logging system
Figure 12 shows one electrode from the cell in detail. A metal grid works as the pick-up electrode, a carbon felt as the working electrode. The solution is circulated in such a way that the electrode is completely wetted.

Figure 13 shows the discharging curve after charging at about $2.9 \mathrm{~V}$ for $60 \mathrm{~s} \mathrm{(A).} \mathrm{The} \mathrm{open} \mathrm{circuit} \mathrm{voltage} \mathrm{is} \mathrm{about}$ $1.2 \mathrm{~V}$. This corresponds to eq. 3. After stopping the circulation (see the star in Figure 13), the voltage decreases to about $0.7 \mathrm{~V}$ (B). After adding a low-current motor as a load, a current of about $20 \mathrm{~mA}$ flows and the voltage decreases to $0.5 \mathrm{~V}(\mathrm{C})$. The motor rotates for about $300 \mathrm{~s}$.

The energy efficiency $\eta=E$ (discharging) / $E$ (charging) $=0.5 * 0.02 * 300 \mathrm{Ws} / 2.9 * 0.3 * 60 \mathrm{Ws} \approx 57 \%$. This is quite satisfactory for such a simple device.

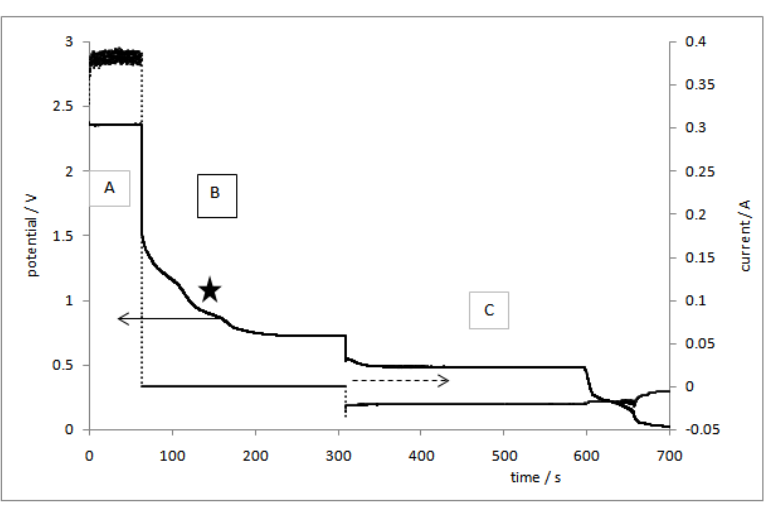

Figure 13. Charging and discharging of a VRFB. A. Charging, B: opencircuit, C: with a motor as load

Figure 14 shows a simple setup to show the color changes after charging (insert) and discharging (large picture).

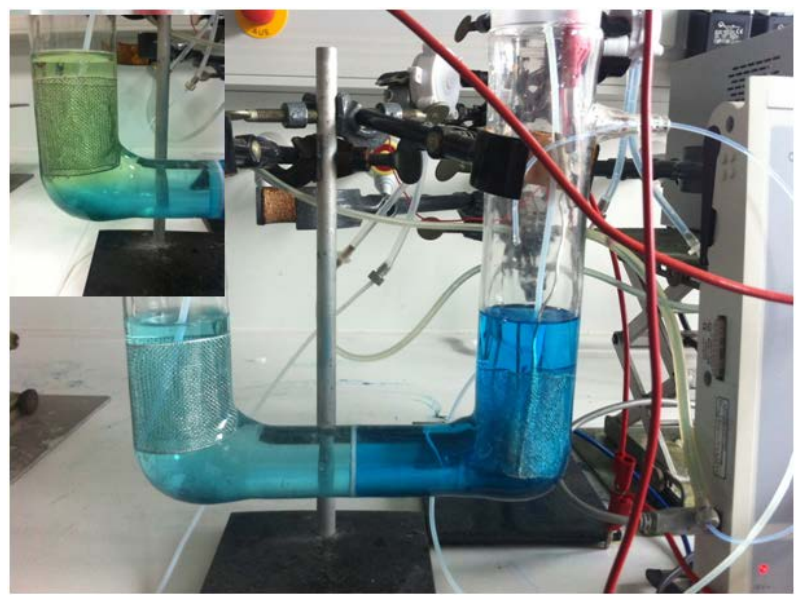

Figure 14. Simple setup that shows the color change of the anode region after charging and discharging

\section{Conclusion}

In this paper we described several spectroscopic and electrochemical methods to investigate VRFBs. All experiments can be performed in about a week (40 hours) in an analytical lab course. By conducting these experiments, students not only improve their experimental skills, but also learn fundamental theoretical aspects about batteries, e.g., cyclic voltammetry, spectroelectrochemical measurements and charge-discharge curves. 
Therefore, we think the versatile investigation of VRFBs is a significant contribution to professional training of students in analytical (electro)chemistry.

\section{Acknowledgements}

A. H. thanks the Vector Foundation (Germany), the Fonds der Chemischen Industrie (Germany), and the Ludwigsburg University of Education for financial support.

\section{References}

[1] A. Parasuraman, T.M. Lim, C. Menictas, M. Skyllas-Kazacos, Review of material research and development for vanadium redox flow battery applications, Electrochim. Act. 2013, 101, 27-40.

[2] O. Venery (Ed.) Technologies and Applications for Smart Charging of Electric and Plug-in Hybrid Vehicles, Springer International Publishing Switzerland 2017.

[3] P. Alotto, M. Guarnieri, F. Moro, Redox flow batteries for the storage of renewable energy: A review, Renew. and Sustain. Energy Rev. 2014, 29, 325-335.

[4] L.H. Thaller, Electrically rechargeable redox flow cells NASA TM X-71540, Lewis Research Center 1974, 1-5.

[5] L. Sanz, D. Lloyd, E. Magdalena, J. Palma, M. Anderson, K. Kontturi, Journal of Power Sources 2015, 278, 175-182.

[6] L. Sanz, D. Lloyd, E. Magdalena, J. Palma, K. Kontturi, Journal of Power Sources 2014, 268, 121-128.

[7] D. Lloyd, E. Magdalena, L. Sanz, L. Murtomaki, K. Kontturi, Preparation of a cost-effective, scalable and energy efficient allcopper redox flow battery, Journal of Power Sources 2015, 292, 87-94.

[8] F.C. Walsh, C. Ponce de Leon, L. Berlouis, G. Nikiforidis, L.F. Arenas-Martinez, D. Hodgson, D. Hall, The Development of ZnCe Hybrid Redox Flow Batteries for Energy Storage and Their Continuing Challenges, ChemPlusChem 2015, 80, 288-311.

[9] P.K.Leung, C. Ponce-de-Leon, C.T.J. Low, A.A. Shah, F.C. Walsh, Characterization of a zinc-cerium flow battery, Journal of Power Sources 2011, 196, 5174-5185.

[10] Z. Xie, Q. Liu, Z. Chang, X. Zhang, The developments and challenges of cerium half-cell in zinc-cerium redox flow battery for energy storage, Electrochimica Acta 2013, 90, 695-704.

[11] R.D. McKerracher, C. Ponce de Leon, R.G.A Wills, A.A. Shah, F.C Walsh, Frank,A Review of the Iron-Air Secondary Battery for Energy Storage, ChemPlusChem 2015, 80, 323-335.

[12] B. Li, Z. Nie, M. Vijayakumar, G. Li, J. Liu Jun, V. Sprenkle, W. Wang, Ambipolar zinc-polyiodide electrolyte for a high-energy density aqueous redox flow battery, Nature communications 2015, 6, 6303.

[13] M. Wu, M. Liu, G. Long, K. Wan, Z. Liang, T.S.A. Zhao, A novel high-energy-density positive electrolyte with multiple redox couples for redox flow batteries, Applied Energy 2014, 136, 576-581.

[14] Z. Chang, X. Wang, Y. Yang, J. Gao, M. Li, L. Liu, Y. Wu, Journal of Materials Chemistry A: Materials for Energy and Sustainability 2014, 2, 19444-19450.

[15] W. Wang, N. Li, N. Liyu, C. Zimin, L. Baowei, S. Qingtao, Y. Shao, X. Wei, C. Xiaoliang, X. Feng, G.G. Xia, Z. Yang, Journal of Power Sources 2012, 216, 99-103.

[16] B. Huskinson, M.P. Marshak, C. Suh, S. Er, M.R. Gerhardt, C.J. Galvin, X. Chen, A. Aspuru-Guzik, R.G. Gordon, M.J. Aziz, Nature (London, United Kingdom) 2014, 505, 195-198.
[17] R.P. Dowd, V. S. Lakhanapel, T.Van Nguyen, Performance Evaluation of a Hydrogen-Vanadium Reversible Fuel Cell, J. Electrochem. Soc. 2017, 164, 564-567.

[18] S.H. Oh, C.W. Lee, D.H. Chun, J.D. Jeon, J. Shim, K.H. Shin, J.H.A. Yang, A metal-free and all-organic redox flow battery with polythiophene as the electroactive species, Journal of Materials Chemistry A: Materials for Energy and Sustainability 2014, 2, 19994-19998.

[19] B. Huskinson, M.P. Marshak, M.R. Gerhardt, M.J. Aziz, Cycling of a quinone-bromide flow battery for large-scale electrochemical energy storage, ECS Transactions 61, (Stationary and Large Scale Electrical Energy Storage Systems 2014, 27-30.

[20] S. Er, C. Suh, M.P. Marshak, A. Aspuru-Guzik, Computational design of molecules for an all-quinone redox flow battery, Chemical Science 2015, 6, 885-893.

[21] L.M. Surhone, M.T. Tennoe, S.F. Henssonow (Ed.), Vanadium Redox Battery. Flow Battery, Vanadium, University of New South Wales, Oxidation State, Storage Battery, $\square$ etascript publishing, Mauritius 2010

[22] A. Parasuraman, T.M. Lim, C. Menictas, M. Skyllas-Kazacos, Review of material research and development for vanadium redox flow applications, Electrochim. Acta 2013, 101, 27-40.

[23] K.J. Kim, M.S. Park, Y-J. Kim, J.H. Kim, S.X Dou, M. SkyllasKazacos, J. Mat. Chem. A: Materials for Energy and Sustainability 2015, 3, 16913-16933.

[24] W.H. Wang, X.D., Investigation of Ir-modified carbon felt as the positive electrode of an all-vanadium redox flow battery, Electrochim. Acta 2007, 52, 6755-6762.

[25] B. Sun, M. Skyllas-Kazacos, Chemical modification and electrochemical behavior of graphite fibre in acid vanadium solutions, Electrochim. Acta 1991, 36, 513-517.

[26] X.L. Zhou, Y.K. Zeng, X.B. Zhu, L. Wei, T.S. Zhao, J. Power Sources 2016, 325, 329-336.

[27] K.J. Kim, S-W. Lee, T. Yim, J-G- Kim, J.W. Choi, J.H. Kim, M-S Park, Y-J. Kim, A new strategy for integrating abundant oxygen functional groups into carbon felt electrode for vanadium redox flow batteries, Sci. Rep. 2014, 4, 6906.

[28] M. Rychcik, M. Skyllas-Kazacos, Journal of Power Sources 1987, 19, 45-54.

[29] F. Rahman, M. Skyllas-Kazacos, Journal of Power Sources 2009, 189, 1212-1219.

[30] M. Skyllas-Kazacos, Maria, C. Peng, M. Cheng, Electrochemical and Solid-State Letters 1999, 121-122.

[31] C. Choi, S. Kim, R. Kim, Y. Choi, S. Kim, H-Y. Jung, J.H. Yang, $\mathrm{H}-\mathrm{T}$. Kim, A review of vanadium electrolytes for vanadium redox flow batteries, Renew. and Sustain. Enegy Rev. 2017, 69, 263-274.

[32] N. Kausar, R. Howe, M. Skyllas-Kazacos, Raman spectroscopy studies of concentrated vanadium redox battery positive electrolytes, J. Appl. Electrochem. 2001, 31, 1327-1332.

[33] M. Skyllas-Kazacos, Journal of Power Sources 2013, 124, 299302.

[34] M. Skyllas-Kazacos, G. Kazacos, G. Poon, H. Verseema, International Journal of Energy Research 2010, 34, 182-189.

[35] T. Mohammadi, M. Skyllas-Kazacos, Characterization of novel composite membrane for redox flow battery applications, Journal of Membrane Science 1995, 98, 77-87.

[36] H. Prifti, A. Parasuraman, S. Winardi, T.M. Lim, M. SkyllasKazacos, Membranes for redox flow battery applications, Membranes 2012, 2, 275-306.

[37] R.S. Nicholson, I. Shain, Theory of Stationary Electrode Polarography Single Scan and Cyclic Methods Applied to Reversible, Irreversible, and Kinetic Systems, Adv. Anal. Chem. 1964, 36, 706-723.

[38] C. Choi, S. Kim, R. Kim, Y. Choi, S. Kim, H-Y. Jung, A review of vanadium electrolytes for vanadium redox flow batteries, Renewable and Sustainable Energy Reviews 2017, 69, 263-274. 